Canadian Journal of Civil Engineering

Canadian

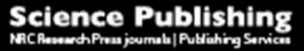
Revue canadienne de génie civil

\title{
CONSTRUCTION PRODUCTIVITY FUZZY KNOWLEDGE BASE MANAGEMENT SYSTEM
}

\begin{tabular}{|r|l|}
\hline Journal: & Canadian Journal of Civil Engineering \\
\hline Manuscript ID & cjce-2017-0540.R1 \\
\hline Manuscript Type: & Article \\
\hline Date Submitted by the Author: & 13-Dec-2017 \\
\hline $\begin{array}{r}\text { Complete List of Authors: } \\
\text { Is the invited manuscript for } \\
\text { consideration in a Special } \\
\text { Issue? : }\end{array}$ & $\begin{array}{l}\text { Elwakil, Emad; Purdue University, School of Construction Management } \\
\text { Environmental Engineering }\end{array}$ \\
\hline Keyword: & model, knowledge base, construction < type of paper to review \\
\hline &
\end{tabular}




\title{
CONSTRUCTION PRODUCTIVITY FUZZY KNOWLEDGE BASE MANAGEMENT SYSTEM
}

\author{
Authors: \\ Emad Elwakil, Assistant Professor, School of Construction Management, Purdue University, West \\ Lafayette, IN, 47907, USA. \\ Tarek Zayed, Professor, Department of Building, Civil \& Environmental Engineering, Concordia \\ University, Montreal, Canada H3G 1M8.
}

\section{Corresponding Author:}

Emad Elwakil PhD, PE, CCP, PMP

Purdue University

School of Construction Management

401 N. Grant St.

West Lafayette, IN, 47907

Phone: 1(765)494-6452

Email: eelwakil@purdue.edu 


\title{
Construction Productivity Fuzzy Knowledge Base Management System
}

\begin{abstract}
Construction companies need a Knowledge Management system in order to collate, share and ultimately apply this knowledge in various projects. One of the most important elements that determine the time estimates of any construction project is Productivity. Such projects have a predilection towards uncertainty and therefore require new generation of prediction models that utilizes available historical data. The research presented in this paper develops, using Fuzzy approach, a knowledge base to analyze, extract and infer any underlying patterns of the data sets to predict the duration and productivity of a construction process. A sixstep protocol has been followed to create this model: (1) determine which factors affect productivity; (2) select those factors which are critical; (3) build the Fuzzy sets; (4) generate the Fuzzy rules and models; (5) develop the Fuzzy knowledge base; and (6) validate the efficacy and function of these models in predicting the productivity construction process. The Fuzzy knowledge base was validated and verified using a case study and the results were satisfactory with $92.00 \%$ mean validity. In conclusion, the developed models/system demonstrated the ability of a knowledge base management to predict the patterns and productivity of different construction operations.
\end{abstract}

\section{INTRODUCTION}

Productivity, defined as "the ratio of output of required quality to the inputs" (Al-Zwainy et. al. 2013), is a vital factor regarding the management of construction projects and predicting the time estimates of specific processes. Various statistical methods, such as probability functions, regression analysis, stochastic techniques, and mathematical curves, have been used to simulate and predict construction processes to optimize management (Bee Hua 2008). However, a limitation of using such statistical analyses is that the raw data can be confounding and ultimately lead to unreliable data mining and modeling (Han and Kamber 2006). Most research unfortunately has focused only on modeling while neglecting proper data preparation. It is imperative that any problems with the raw data are identified before starting the modeling process. The most common problems with raw data are missing data and outliers, which need to be identified and then removed. This process of obtaining useful and hidden information from 
extensive data sets is known as data mining. Since this is not possible with the standard statistical methods, an inter-disciplinary domain called Knowledge Discovery in Database (KDD) was created for identifying patterns in data and mining the useful parts (Fayyad et. al 1996). The KDD uses concepts from basic mathematics, statistics, machine learning, database query, and visualization (Anand et al. 1998). However, most modern KDD tools focus largely on building models rather than data mining (Cox and Wills 1997). Although 60\% of the time goes into data preparation, only $10 \%$ of the overall effort is utilized in the actual mining step (Cabena et al. 1998). KDD ideally comprises of data understanding and data preparation, data mining, pattern detection and finally application (Chapman et al. 1999). KDD has also been applied to the construction industry since the rapid increase in computerized historical databases (Buchheit et al. 2000; Soibelman and Kim 2002). In addition, a data warehouse application to gather data insights and support decision making was developed by Chau et al. (2002) to aid the construction industry.

\section{RESEARCH OBJECTIVES}

The main objective of this study is to check the ability of a knowledge base management system to predict the patterns and productivity of different construction operations. This objective is to be achieved via successive steps as outlined below:

- Design a model to utilize and extract the underlying patterns from the raw project data.

- Integrate this extracted and usable data from past/historical sources with the knowledge base design to predict construction productivity.

- Verify and validate the knowledge base using a case study.

\section{BACKGROUND}

The idea of knowledge management (KM) was first articulated by Horton (1979) in a research monograph. The 1980s was marked by a greater awareness of KM with analysts such as Rogers, and Edvinsson who began appreciating this concept (Edvinsson 1987; Rogers 1987). KM was finally recognized as a branch of science in 1991(Nonaka 1991) and began garnering more attention from the 1990s onwards (Nonaka and Takeuchi 1995). Since the dawn of new millennium, various large organizations and companies have been relying on knowledge as a 
vital asset, needed in order to maintain their competitive edge in the market (Bruton et al. 2007; McRea and Langdon 2003; Senaratne and Sexton 2009; Yu and Yang 2016). However, the research available on $\mathrm{KM}$ in the civil infrastructure and construction industry is unplanned and fragmented, in part due to the rapid changes this field has seen in the past years and decades. It is imperative therefore to collect and analyse historical data, identify any unique patterns and use this information to predict future trends (Deng 2007; Yu and Yang 2016).

Since research into the construction management is based on the fuzzy set theory, fuzzy logic, and hybrid fuzzy techniques, many studies attempted to combine those techniques with artificial neural networks to create an optimized hybrid model to study the effect of various factors on productivity (Bee Hua 2008). As examples, the National Electrical Contractors Association (NECA) studied the effect of seasonal factors such as humidity and temperature on labor productivity (Sonmez \& Rowings 1998) while another study correlated multiple factors with specific construction tasks with the help of regression analysis and neural network modeling (Sonmez \& Rowings 1998). In addition, a number of mathematical models such as the straightline power model, cubic power model exponential model and piecewise model have been used to create learning curves that predict future trends (Thomas et. al. 1986). In this study, the learning curve showed that an increase in product output by a factor of two is correlated with a decrease in man-hours and other costs by a fixed percentage of the previous costs. The most reliable and therefore the most commonly used mathematical curve model in construction productivity is the straight-line power model (Everett and Farghal 1994). Some recent studies have applied the learning curves to virtual construction processes (Hildreth 2012) while others have used algorithms to evaluate these mathematical curves and their ability to predict future performance (Malyusz and Pem 2014).

The main factors affecting productivity are the labor, weather, materials, time and changing requirements (Park 2006). In addition to identifying these initial factors, it is also important to review data from previous projects and use that as the foundation for building up the prediction model. For example, the WEATHER system was developed to evaluate the impact of weather conditions on construction productivity and to study past weather patterns for better scheduling (Moselhi 1997). In addition to building this model, Moselhi et al. (1991) studied as many as 57 different projects to find any correlation between order change and productivity and found a direct link between changing labor requirements and lowered productivity. Models based on 
historical data help better forecast trends and predict overall productivity with greater accuracy (Mirahadi \& Zayed 2016). Other notable examples include the study of Lv and El-Gohary (2016) which used text analytics to main stakeholders' opinions for highway construction projects and a Fuzzy Knowledge Approach developed by Elwakil and Zayed (2014) as a means to extract data for accurate prediction of task duration. Despite the prevalence of KM systems in data mining and pattern finding, the use of historical data is still lacking. Therefore, the models build with the current data systems do not represent the knowledge in its entirety that would be essential for predicting construction productivity (Soibelman and Kim 2002; Soibelman et al. 2004; Reffat et al. 2006; and Mougel et al. 2010; Guns 2016; and Silva and Antunes 2016).

\section{RESEARCH METHODOLOGY}

The research methodology consists of five phases - a) an exhaustive literature review on the current trends in data mining pertaining to the construction industry as well as building a Fuzzy knowledge base; b) development and implementation of steps that include Variable Selection, Fuzzy Sets, Fuzzy Rule Induction, and Fuzzy Knowledge Base; c) data collection and verification of the developed system; d) validation of the said system using a case study; and e) conclusions and future directions. Each of the aforementioned steps are explained in detail below.

\section{PRODUCTIVITY DATA MANAGEMENT SYSTEM DEVELOPMENT}

The following functional steps make up the system - variable selection, Fuzzy sets formation, Fuzzy rules' induction and Fuzzy knowledge base construction. The knowledge base is finalized only after it passes a validation process with an acceptable percentage.

\subsection{Variables selection}

All the variables that can potentially affect the output and productivity are selected. Fuzzy average method is commonly used and begins with producing the fuzzy curve and then ranking those variables (Lin et al.1996). The Fuzzy modeling has been used to avoid the effect of correlation using Membership Functions instead of Crisp sets as the correlation between 
variables or attributes, the correlation coefficients defined on ordinary crisp sets (Chiang \&Lin 1999; Ye 2014; Tyagi 2015).

\section{a. Producing the fuzzy curve}

The following steps are used to produce a Fuzzy curve:

1- Plot the $\mathrm{M}$ data points $(\mathrm{Xi}, \mathrm{Yj}), \mathrm{k}=1,2 \ldots . . \mathrm{M}$, in each xi-y space, $\mathrm{i}=1,2, \mathrm{~N}$ For each input variable xi.

2- Create fuzzy membership function for each data point $(\mathrm{Xi}, \mathrm{Yj})$ in each xi-y space using Equation 1 to calculate the membership function for each input and output variables (Xi,Yj) (Lin and Cunningham 1995).

$$
\left.\mu i, k\left(x_{i}\right)=\exp \left(\frac{\mathrm{Xi}, \mathrm{k}-x \mathrm{i}}{b}\right)^{2}\right)
$$

Where:

$\mathrm{K}: 1,2,3 \ldots, \mathrm{M}$

b: The width of the influence interval is $20 \%$ of variable range

3- Create a fuzzy curve ci point for each data point by 'de-fuzzifying' the fuzzy membership functions to produce a fuzzy curve, using Equation 2.

$$
\operatorname{ci}(\mathrm{xi})=\frac{\sum_{\mathrm{k}=1}^{\mathrm{M}} \mathrm{yk} * \mu \mathrm{i}, \mathrm{k}(\mathrm{xi})}{\sum_{\mathrm{k}=1}^{\mathrm{M}} \mu \mathrm{i}, \mathrm{k}(\mathrm{xi})}
$$

\section{b. Ranking the variables}

The variables are ranked using the Mean Square Error (MSE). The MSE is calculated for each Fuzzy curve and the input variables are ranked in the ascending order of their MSEs using Equation 3. The relationship between the input and output is only significant when the MSE value is small. A large MSE value indicates a complete lack of correlation between the input and 
output and the Fuzzy curve ends up being flat. In other words, the input variable with smallest MSE is the most significant and that with highest MSE value is the least important.

$$
M S E c i=\frac{1}{M} \sum_{k=1}^{M}(c i(x i, k)-y k)^{2}
$$

\subsection{Forming the Fuzzy sets - 'Fuzzification'}

The tangible or 'crisp' quantitative variables are converted into Fuzzy sets during this step. This begins with identifying some of the underlying uncertainties in these values and then converting them to fuzzy values. Each crisp quantity is assigned a membership value with the help of a neural network which uses historical data to build up the membership functions. The neural network in turn is modeled using data sets of selected variables, which then uses these same values to self-train. The training is suitably programmed to simulate the relationship between the coordinate locations and membership values and continued till the network can simulate all the input and output values. This is followed by validating the network using test data and when finally ready, is used to determine the membership value of any input data set in any location.

The network is build up using data in the form of clusters: say Ci represents the cluster numbers, Rij the membership function values (output), Xij the data points of the variables (input) and random values are assigned to all the weights connecting the paths between the elements in the layers of the network $\mathrm{W}^{\mathrm{n}}{ }_{\mathrm{nn}}$, the outputs can be calculated using Equation 4 below (Takagi and Hayashi, 1991). To test the network, an input value of $\mathrm{x}$ is passed through it and the network computes an output value ( $\mathrm{f}(\mathrm{x})$ output) which is compared to the actual value ( $\mathrm{f}(\mathrm{x})$ actual $=\mathrm{y})$. The error measure $\mathrm{E}$ is computed from these two output values using Equation 5. This error is linked with the last layer of the neural network and is distributed to the elements in the hidden layers via the back propagation technique using Equation 6 (Takagi and Hayashi 1991). When 
the errors associated with each element in the network are known, the weight of each of these elements is calculated using Equation 7 (Takagi and Hayashi 1991). In this way, the neural network is able to approximate the actual output closely. The Xij is again passed through the network, this time with the updated weights and the errors are calculated again. This entire procedure is repeated until the error value of the final output is within certain limits or remains constant. Finally, a validation data set is used to feed through the network to simulate the relationship.

$$
\mathrm{O}=\frac{1}{1+\exp \left[-\left(\sum \text { xiwi-t }\right)\right]}
$$

\section{Where:}

$\mathrm{O}$ : output of the threshold element computed using the sigmoidal function

xi : inputs to the threshold element $(i=1,2, \ldots, n)$

wi : weights attached to the inputs

$\mathrm{t}$ : threshold for the element

$$
\begin{array}{ll}
\mathrm{E}=\mathrm{f}(\mathrm{x})_{\text {actual }}-\mathrm{f}(\mathrm{x})_{\text {output }} & \text { (Equation 5) } \\
\mathrm{E}_{\mathrm{n}}=\mathrm{O}_{\mathrm{n}}\left(1-\mathrm{O}_{\mathrm{n}}\right) \sum_{\mathrm{j}} \mathrm{w}_{\mathrm{nj}} \mathrm{E}_{\mathrm{j}} & \text { (Equation 6) } \\
\mathrm{w}_{\mathrm{jk}}^{\mathrm{i}}(\mathrm{new})=\mathrm{w}_{\mathrm{jk}}^{\mathrm{i}}(\mathrm{old})+\alpha \mathrm{E}_{\mathrm{k}}^{\mathrm{i}+1} \mathrm{x}_{\mathrm{jk}} & \text { (Equation 7) }
\end{array}
$$

Where: wijk: represents the weight associated with the path connecting the $\mathrm{j}^{\text {th }}$ element of the $\mathrm{i}^{\text {th }}$ layer to the $\mathrm{k}^{\text {th }}$ element of the $(i+1)^{\text {th }}$ layer

$\alpha$ : learning constant

$E_{k}^{i+1}$ : error associated with the $k^{\text {th }}$ element of the $(i+1)^{\text {th }}$ layer; and $\mathrm{x}_{\mathrm{jk}}$ : input from the $\mathrm{j}^{\text {th }}$ element in the $\mathrm{i}^{\text {th }}$ layer to the $\mathrm{k}^{\text {th }}$ element in the $(\mathrm{i}+1)^{\text {th }}$ layer $\left(\mathrm{O}_{\mathrm{ij}}\right)$. 


\subsection{Fuzzy rules induction}

This step is used to determine the functional relationship between each of the independent variables' membership values and the dependent variables (e.g task duration) in order to generate actual models. The aim of Fuzzy Rule induction is to create a knowledge base of fuzzy 'if-then' rules which describe this functional relationship as well as trends in a large collection of data sets. This step is a supervised knowledge discovery approach since it is concerned with at-least one dependent or outcome variable and a wider set of independent variables. The concept of a rule-based model is to understand what a particular data means and how it can be extracted and applied. There are two steps in the rule induction process:

\section{a. Generation of Candidate Fuzzy Rules}

The fuzzy sets discussed in the previous sections are used as the input variables and the relationship between the dependent and independent variables is determined as follows:

\section{i. Isolation of the fuzzy sets into individual data points}

The fuzzy sets that are isolated to data points with the highest membership degree - possible when two data sets occur in the same fuzzy set - are selected.

\section{ii. Conversion of all fuzzy relations to rules}

The fuzzy relations are converted into the if-then rules with the help of certain standardized rules, without any relation to the data set. Each rule is then separated in a final rule selection process.

\section{b. Selection of the Final Rule Set}

The final rules are selected from a vast pool of data pairs and to avoid any conflicts, the degree of effectiveness (E) for each rule is computed and the most effective rules amongst them are 
selected. The effectiveness of each rule is the product of its component of fuzzy set membership degree, as shown in Equation 8 (Cox 2005).

$$
\mathrm{E}(\mathrm{ri})=\mu \mathrm{x}(\mathrm{v} 1) \times \mu \mathrm{y}(\mathrm{v} 2) \times \mu \mathrm{z}(\mathrm{v} 3) \quad \text { (Equation 8) }
$$

\subsection{Fuzzy knowledge base (FKB)}

The combination of all previous steps - variables, fuzzy sets and fuzzy rules - results in the fuzzy knowledge base. The FKB, although not a complete representation of a system, can represent a model and a collection of FKBs may approximate a complex system. The FKBs store the variables, concept hierarchies to organize attributes and the rules required to solve a set of outcomes associated with the system. The FKB needs to be validated before it is finalized.

\subsection{Validation}

A mathematical validation process will be used to determine how effectively the FKB can predict. The average invalidity percent (AIP) and the Average Validity Percent (AVP) will be calculated using Equation 9 and 10 respectively. AIP value closer to 0.0 indicates soundness of the model while a value closer to 100 indicates failure (Zayed and Halpin 2005). The Root Mean Square Error (RMSE) is calculated using Equation 11. As with AIP value, RMSE values closer to 0 indicates that the model is sound and closer to 100 indicates failure. The Mean Absolute Error (MAE) is calculated using Equation 12 and its value ranges from 0 to infinity. However, the MAE should be close to zero for sound results (Dikmen et al. 2005).

$$
\begin{array}{lr}
A I P=\left(\sum_{i=1}^{n}\left|1-\left(E_{i} / C_{i}\right)\right|\right) * 100 / n & \text { (Equation 9) } \\
A V P=100-A I P & \text { (Equation 10) } \\
R M S E=\frac{\sqrt{\sum_{\mathrm{i}=1}^{\mathrm{n}}\left(\mathrm{C}_{\mathrm{i}}-\mathrm{E}_{\mathrm{i}}\right)^{2}}}{\mathrm{n}} & \text { (Equation 11) } \\
M A E=\frac{\sum_{\mathrm{i}=1}^{\mathrm{n}}\left|\mathrm{C}_{\mathrm{i}}-\mathrm{E}_{\mathrm{i}}\right|}{\mathbf{n}} & \text { (Equation 12) } \\
\text { Where: } & \\
A I P: \text { Average Invalidity Percent } & A V P: \text { Average Validity Percent }
\end{array}
$$


$R M S E$ : Root Mean Squared Error

$E_{i}$ : Estimated Value
$M A E$ : Mean Absolute Error

$C_{i}$ : Actual Value

\section{ANALYSIS AND IMPLEMENTATION TO A CASE STUDY}

The field observations and data collection were carried out for a period of eighteen months on an under-construction building: The Engineering, Computer Science and Visual Arts Complex of Concordia University. It is a 17 -storey integrated educational facility with a surface area of 86,000 square meters. For this paper, the process of concrete pouring was considered.

\subsection{Data collection process}

Data acquisition from historical records is a cost-effective approach as shown by Khan (2005) and Wang (2005) while studying labor productivity. The data for this study was collected from publicly available data records such as Infrastructure Canada and weather networks on the internet. As shown in Figure 1, there were four groups of variables: a) weather - temperature, b) crew - labor size, c) project type - methods and d) operational - drivers and transportation. Both qualitative and quantitative variables, as shown in Table 1, from each group have been studied for their effect on productivity. The time of concrete pouring operations, which included pouring, hauling, loading and return times was recorded at the jobsites. These processes are outlined in Figure 2.

\section{Insert Figure 1}

\section{i. Concrete Pouring Process}

The concrete pouring process is the first process in the concrete pouring operation and dependent on eight variables - precipitation and method which are qualitative variables, and temperature, 
humidity, wind speed, gang size, labor percentage and floor level, which are the quantitative variables as shown in Table 2. A total of 95 data points was collected and used in the modeling and validation processes.

\section{Insert Table 1}

\section{ii. Hauling process}

Hauling depends on six variables - precipitation, driver skills, truck status, and road conditions (qualitative), and temperature and wind speed (quantitative) as shown in Table 3. One hundred and ten data points were collected for the modeling and validation processes.

\section{Insert Figure 2}

\section{Insert Table 2}

\section{Insert Table 3}

\section{iii. Loading process}

Loading also depends on six variables - only one qualitative i.e. precipitation and five quantitative including temperature, humidity, wind speed, gang size and labor percentage as shown in Table 4. One hundred data points were collected for this process.

\section{Insert Table 4}




\section{iv. Return process}

The final process in the loading operation is returning which is influenced by six variables precipitation, driver skills, truck status, and road condition (qualitative) and temperature and wind speed (quantitative) as shown in Table 5. One hundred and ten data points were collected for the modeling and validation processes. As shown in Figure 3, several data points were randomly removed from the data sets to check the validity of the proposed system.

\section{Insert Table 5}

As indicated in Figure 4, the statistical parameters and probability density functions were calculated for all variables that affect the processes. The probability Density functions have been generated using Minitab software to specify the probability of the random variable falling within a particular range of values, as opposed to taking on any one value. This probability is given by the integral of this variable's PDF over that range (Minitab 2000). Figure 3 shows for each variable the number of points in each data set and number of missing data. In addition to being presented in graphs, some common parameters often can be used to describe sets of numbers.

\section{Insert Figure 3}

\section{Insert Figure 4}




\subsection{Selection of variables}

The variables affecting the output i.e. work task duration were selected using the fuzzy average method and to validate this method, it was compared to the outputs of Artificial Neural Network (ANN) and Regression methods.

\section{a. Building fuzzy curve}

A fuzzy curve was built by plotting the data points $(\mathrm{Xi}, \mathrm{Yj})$ in the (xi-yi) space for all variables and fuzzy membership functions were then created for each data point $(\mathrm{Xi}, \mathrm{Yj})$ and for each input and output variable as shown in Equation 1. A fuzzy curve ci point was created for each set of data points by 'defuzzifying' the fuzzy membership functions using Equation 2. As an example, fuzzy curve for "Gang Size" is shown in Figure 5. A flat fuzzy curve indicates a completely random relationship between the input and output variables whereas a positive or negative shaped curve shows a strong relation.

\section{b. Ranking}

The variables are ranked using the Mean Square error (MSE) as shown in Equation 3. As already described, larger MSE values indicate a poor representation of the input-output relation by the fuzzy curve resulting in a flat curve while smaller values mean that the relationship is significant. The mean square error MSE was calculated for each fuzzy curve as shown in Table 6. All the variables were ranked according to the ascending order of the MSE as shown in Table 7. In order to validate the fuzzy average method, ANN and Regression methods were used to compare the ranking of the selected variables described below.

\section{Insert Figure 5}

\section{Insert Table 6}




\section{Insert Table 7}

\section{1- Variables Selection Using the ANN Method}

Input variables need to be ranked in order to determine the relative importance of each variable on the duration of the process. The contributing percentages of each of the variables are then derived with the help of a trained neural network. The higher the number, greater the contribution of that variable to making an accurate prediction. Table 8 shows the contribution percentage (relative significance) of eight variables. By comparing the results of fuzzy average method and ANN methods, it was clear that four out of the eight variables have similar rankings while the other variables have different rankings. In addition, the last-ranked variable - the method variable - was the same as per both approaches. However, the $\mathrm{R}^{2}$ for ANN model $(88.8$ \%) was lower than that of the fuzzy average method model indicating that the latter is more robust in ranking variables.

\section{Insert Table 8}

\section{2- Variables Selection using Regression Method}

The Regression method simply shows the best subset of variables instead of their contributing percentages. Table 9 lists the status of the contribution of the eight variables. A comparison of the fuzzy average method with regression revealed that six of the eight variables were included in the regression model. The remaining two were not included since they had less contribution to 
the fuzzy average method model. The $\mathrm{R}^{2}$ for the regression model $(88 \%)$ was lower than the fuzzy average method indicating the greater efficacy of the latter.

\section{Insert Table 9}

From the two comparisons, we can conclude that the fuzzy average method works better when the relationship between the variables is unclear. As a result, the fuzzy approach improved the modeling of qualitative variables and the relation between the qualitative variables and process durations.

\subsection{Fuzzy sets conversion}

This step converts the crisp quantities into fuzzy sets by identifying some of the uncertainties present in the crisp values. As mentioned in the previous sections, the conversion to fuzzy values is represented by the membership functions which are assigned for each given quantity - a process called 'fuzzification'. Membership values were assigned using the neural network technique to model the relation between the fuzzy membership functions and process duration and predict the duration.

\subsection{Fuzzy rule induction}

The goal of this step is to model the functional relationship between independent variables' membership values and dependent variables (Task Duration) as a set of fuzzy if-then rules as shown in Table 10. First, the actual models of the underlying processes are generated and then 
induction rule is used to create a knowledge base of fuzzy if-then rules which model one or more trends in a large collection of data sets.

\section{Generation of the candidate fuzzy rules}

The inputs of this process are fuzzy sets, model variables and system definitions, which have been already discussed. The fuzzy relations are produced from both dependent and independent variables and the converted to "If-Then" rules, as shown in Table 11.

\section{a. Selection of a final rule set}

The final rules were selected from all of the candidate rules presented in Table 11, which are essentially repetitive rules representing the same duration. The effectiveness of each rule was calculated using Equation 8 and the highest effectiveness-degree rules were selected, as shown in Table 12. For instance, Rule 36 was replaced by Rule 24 due to the degree of effectiveness. The selection of the final rules should decrease the number of rules without affecting the performance of the rules system.

\section{Insert Table 10}

\subsection{Fuzzy knowledge base}

A fuzzy knowledge base includes all the previous steps, i.e. the selected variables, fuzzy sets, and fuzzy rules. As shown in Table 13, the FKB is a representation of a separate model of each process, meaning that the concrete pouring process and the loading process each will have a different FKB. A collection of FKBs cooperates to form a solution to a concrete pouring operation.

\subsection{Fuzzy knowledge base validation}


To test the prediction efficacy of this system, a validation data set was embedded into the developed FKB and its results were compared with the actual data. The first test was to compare the actual and the predicted plots and the results were satisfactory; briefly, the predicted values were within acceptable limits and scattered around the actual values, as shown in Figure 6. The second test was a mathematical and descriptive validation using the Equations 9 to 12. The average invalidity percent (AIP), which denotes the prediction error, was calculated using Equation 9. A sound model has an AIP value closer to 0 while an unsound one has values closer to 1 . Equation 11 was used to calculate the root mean square error (RMSE), which, at values closer to 0 indicated sound model and vice versa. Finally, Equation 12 was used to calculate the mean absolute error (MAE) which lies between 0 and infinity, but should be close to 0 for an optimum model. The results of these equations are summarized in Table 14.

\section{Insert Table 11}

The AIP was 92\%, RMSE was 2 and the MAE was 5. Therefore, the fuzzy knowledge base developed in this study is acceptable, robust, and can be applied for further steps. The aim of setting more than one validation point in this system was to improve the simulation process and aid the decision maker in improving the entire modeling process. For instance, if the validation is not acceptable after the data mining phase, the decision maker has to improve the data sets by simply increasing the number of data points or by collecting other data sets with different data quality rules. Since this validation process was satisfactory completed, the Knowledge Discovery Stage (KDS) can present the data to the Simulation Stage (SS). There KDS prepared data differs from that of the other available simulation systems: (1) the data is clean and complete without 
any fuzziness; (2) to have access to all data patterns, the outliers are separated in special clusters for the simulation process; (3) the qualitative and quantitative variables are considered while predicting the processes' durations; (4) historical data plays an important role in predicting the duration, rather than vague probabilities and expert opinions; (5) the input data can be controlled through a validation procedure to improve the modeling and simulation procedure; and (6) the procedure to predict durations is easier and more accurate.

\section{Insert Table 12}

\section{Insert Table 13}

\section{Insert Table 14}

\section{Insert Figure 6}

\section{CONCLUSIONS}

The research presented in this paper uses data mining, and construction knowledge base to extract hidden patterns from data sets to improve productivity in the construction industry. The efficacy of data mining depends on collecting historical data and identifying the variables which affect the construction processes. Our results show that various qualitative and quantitative variables have significant effect on task duration and productivity. We were able to show that the fuzzy approach is effective in modeling the hidden patterns of construction data sets and validated this system with $92.00 \%$ average validity percent. The knowledge base management systems (KBMS) can predict the duration of different construction processes and can therefore benefit both researchers and practitioners. The main component of (KBMS) is the Knowledge Discovery Stage (KDS) where the Patterns are extracted, which implicitly represent knowledge that is stored or captured 
in large databases. This stage models the effect of qualitative and quantitative variables on the construction process. The KDS includes data cleaning, integration, selection, transformation, and mining as well as pattern evaluation and knowledge presentation. This research presents the following contributions to the state of the art in construction knowledge base management systems: 1) Develops a strategy and methodology to manage the uncertainties in a project productivity; and 2) Integrates the enormous amount of historical data and design into a fuzzy knowledge base that can be used to predict process' productivity instead of approximated probability distribution.

There are however several limitations and delimitations of this system which need to be addressed in future studies: a) the relation between variables affecting the project e.g. management and organization of the project; and their overall effect on the construction operations should also be studied; b) it is important to address the relation between the number of variables and the number of data points in order to enhance predictive potential. This is because if data size is increased, there might be a chance of improving the prediction of the process duration. In case of limited data sets, it will be helpful to use indices and graphs with a reliable threshold of the number of variables and data sets; and c) Study more variables which might affect productivity. For example, for the Concrete Pouring Process, like concrete placement method including: concrete pump, direct chute, conveying, crane and bucket, etc. Some of these methods would be more suitable for a horizontal (e.g. SOG) than to a vertical (e.g. wall) placement. Similarly, whether the condition (status) of the equipment used in the direct placement has an effect on the productivity or not. Some equipment might be inefficient due to lack of maintenance for the concrete pump, old or inefficient compressor, etc. 


\section{REFERENCES}

Al-Zwainy, F. M. S., Abdulmajeed, M. H., \& Aljumaily, H. S. M. 2013. Using Multivariable Linear Regression Technique for Modeling Productivity Construction in Iraq. Open Journal of Civil Engineering, 03(03), 127-135. doi:10.4236/ojce.2013.33015

Anand, S. S., Patterson, D., Hughes, J. G., Bell, D.A. 1998.Discovering case knowledge using data mining. Proceedings of the Second Pacific-Asia Conference in Knowledge Discovery and Data Mining (PAKDD), Melbourne, Australia, 1998; pp.25-35

Arditi, D., \& Mochtar, K. 2000. Trends in productivity improvement in the US construction industry. Construction Management and Economics, 18(1), 15-27. doi:10.1080/014461900370915

Bee Hua, G. 2008. The state of applications of quantitative analysis techniques to construction economics and management (1983 to 2006). Construction Management and Economics, 26(5), 485-497. doi:10.1080/01446190801998716

Bruton, G., Dess, G., \& Janney, J. 2007. Knowledge management in technology-focused firms in emerging economies: caveats on capabilities, networks, and real options. Asia Pacific Journal of Management, 24(2), 115-130.

Buchheit, R.B., Garrett, J.H., Lee, S.R. and Brahme, R., 2000. A knowledge discovery framework for civil infrastructure: a case study of the intelligent workplace. Engineering with Computers, 16(3-4), pp.264-274.

Cabena, P., Hadjinian, P., Stadler, R., Verhees, J., \& Zanasi, A.1998. Discovering data mining from concept to implementation 1998; NJ: Prentice Hall.

Chapman, P., Clinton, J., Khabaza, T., Reinartz, T., \& Wirth, R. (1999). The CRISP-DM process model. The CRIP-DM Consortium, 310.

Chan, A. P., Chan, D. W., \& Yeung, J. F. 2009. Overview of the application of "fuzzy techniques" in construction management research. Journal of Construction Engineering and Management, 135(11), 1241-1252. Retrieved from http://ascelibrary.org/doi/abs/10.1061/(ASCE)CO.1943-7862.0000099

Chau, K.W., Cao, Y., Anson, M. and Zhang, J., 2002. Application of Data Warehouse and Decision Support System in Construction Management. Automation in Construction, 12(2), pp.213-224.

Chiang, D. A., \& Lin, N. P.1999. Correlation of fuzzy sets. Fuzzy sets and systems, 102(2), 221226.

Choy, E., \& Ruwanpura, J. Y. 2006. Predicting construction productivity using situation-based simulation models. Canadian Journal of Civil Engineering, 33(12), 1585-1600.

Cox, E. 2005. Fuzzy modeling and genetic algorithms for data mining and exploration Morgan Kaufmann Publishers, Elsevier. 
Cox, E., Wills, B. 1997. Visual Data Mining: Recognizing Telephone Calling Fraud. Data Mining and Knowledge Discovery, Vol. 1, 1997; pp. 225-231.

Dikmen, I., Birgonul, M. T., \& Kiziltas, S. 2005. Prediction of organizational effectiveness in construction companies. Journal of Construction Engineering and Management, 131, 252.

Deng, G. 2007. Simulation-based optimization. Ph.D. thesis, University of Wisconsin-Madison.

Deogun, J. Spaulding, W. Shuart, B., Li, D. 2004.Towards Missing Data Imputation: A study of fuzzy K-means Clustering Method, In Rough Sets and Current Trends in Computing. Lecture Notes in Computer Science 3066, Springer-Verlag, 2004, pp.573-579.

Edvinsson, L. 1987. The new business focus. Service Industries Journal, 7(7), 195-206.

Elwakil, E., \& Zayed, T. 2014. Construction knowledge discovery system using fuzzy approach. Canadian Journal of Civil Engineering, 42(1), 22-32.

Everett, J.G. and Farghal, S., 1994. Learning curve predictors for construction field operations. Journal of construction engineering and management, 120(3), pp.603-616.

FAHW.2014. Federal Highway administration Policy. Retrieved from : https://safety.fhwa.dot.gov/tools/data_tools/mirereport/29.cfm.

Fayyad, U, Piatetsky-Shapiro, G. Smyth, P.1996. From data mining to knowledge discovery: an overview, Advances in knowledge discovery and data mining. American Association for Artificial Intelligence, Menlo Park, CA, 1996.

Guns, T. 2016. Towards generic and efficient constraint-based mining, a constraint programming approach. In Proceedings of the 16ieme Journees Francophones Extraction et Gestion des Connaissances (EGC) (pp. 13-20).

Han, J., Pei, J., \& Kamber, M. 2011. Data mining: concepts and techniques. Elsevier. San Francisco, CA.

Hildreth, J. 2012. Using Construction Equipment Simulators to Teach Learning Curve Theory Paper presented at 2012 ASEE Annual Conference \& Exposition, San Antonio, Texas. https://peer.asee.org/22179

Horton, F. W. 1979. Information resources management: concept and cases. Ohio: Association for Systems Management Press.

Khan, Z. U. 2005. Modeling and parameter ranking of construction labor productivity. Master's thesis, Concordia University.

Kivrak S, Arslan G, Dikmen I, Birgonul, MT. 2008. Capturing knowledge in construction projects: knowledge platform for contractors. 2008, Journal of engineering Management, volume 24:pp 87-95.

Lin, Y., Cunningham, G. A., \& Coggeshall, S. V. 1996. Input variable identification-fuzzy curves and fuzzy surfaces. Fuzzy sets and systems, 82(1), 65-71. 
Lv, X. and El-Gohary, N., 2016. Text Analytics for Supporting Stakeholder Opinion Mining for Large-scale Highway Projects. Procedia Engineering, 145, pp.518-524.

Malyusz, L., \& Pem, A. 2014. Predicting Future Performance by Learning Curves. ProcediaSocial and Behavioral Sciences, 119, 368-376.

McRea, A., \& Langdon, D. 2003. Knowledge management in construction. Structural Engineering, 81(13), 14.

Minitab, I. N. C. 2000. MINITAB statistical software. Minitab Release, 13.

Mougel, P. N., Plantevit, M., Rigotti, C., Gandrillon, O., \& Boulicaut, J. F. 2010. Constraintbased mining of sets of cliques sharing vertex properties. ACNE, 10, 48-62.

Moselhi, O., Gong, D., El-Rayes, K., 1997.Estimating weather impact on the duration of construction activities, Can. J. Civ. Eng. 24 (3) (1997) 359-366.

Moselhi, O., Leonard, C., Fazio, P. 1991.Impact of change orders on construction productivity, Can. J. Civ. Eng. 18 (3) (1991) 484-492.

Nonaka, I. 1991. The knowledge creating company. Harvard Business Review, 69(6), 96-104.

Nonaka, I., \& Takeuchi, H. 1995. The knowledge creating company. Oxford: Oxford University Press.

Park, H. 2006. Conceptual framework of construction productivity estimation, KSCE J. Civ. Eng. 10 (5) (2006) 311-317.

Mirahadi, F., \& Zayed, T. 2016. Simulation-based construction productivity forecast using neural-network-driven fuzzy reasoning. Automation in Construction, 65, 102-115.

Reffat, R. M., Gero, J. S., \& Peng, W. 2006. Improving the management of building life cycle: A data mining approach. Innovation International Conference, 25 - 27 October 2004, Surfers Paradise, Australia.

Rogers, D. M. A. 1987. Opening remarks - roundtable on critical issues: management of knowledge assets into the 21st century. Journal of Technology Transfer, 11(2), 75-79.

Senaratne, S., \& Sexton, M. 2009. Role of knowledge in managing construction project change. Engineering Construction and Architectural Management, 16(2), 186-200.

Silva, A., \& Antunes, C. 2016. Constrained pattern mining in the new era. Knowledge and Information Systems, 47(3), 489-516.

Soibelman, L. and Hyunjoo, K. 2002.Data Preparation Process for Construction Knowledge Generation through Knowledge Discovery in Databases. Journal of Computing in Civil Engineering, American Society of Civil Engineers (ASCE), January 2002, Volume 16, Number 1 pp 39-48. 
Soibelman L, Liu L, and Wu, J. 2004.Data Fusion and Modeling for Construction Management Knowledge Discovery 10th International Conference on Computing in Civil and Building Engineering, June, 2004, Weimar, Germany.

Sonmez, R., \& Rowings, J. E. 1998. Construction labor productivity modeling with neural networks. Journal of Construction Engineering and Management, 124(6), 498-504. Retrieved from http://ascelibrary.org/doi/abs/10.1061/(ASCE)0733-9364(1998)124:6(498)

Takagi, H., \& Hayashi, I. 1991. NN-driven fuzzy reasoning. International Journal of Approximate Reasoning, 5(3), 191-212.

Thomas, H. R., C. T. Mathews, and J. G. Ward, 1986. Learning Curve Models of Construction Productivity. Journal of Construction Engineering and Management, ASCE, 112(2), 245-258.

Tyagi, S. K.2015. Correlation coefficient of dual hesitant fuzzy sets and its applications. Applied mathematical modelling, 39(22), 7082-7092.

Wang, F., 2005.On-Site labor productivity estimation using neural networks. Master's thesis, Concordia University, Montreal, Canada

Ye, J., 2014. Correlation coefficient of dual hesitant fuzzy sets and its application to multiple attribute decision making. Applied Mathematical Modelling, 38(2), 659-666.

Yu, D., \& Yang, J. 2016. Knowledge Management Research in the Construction Industry: a Review. Journal of the Knowledge Economy, 1-22.

Zayed, T. M., \& Halpin, D. W. 2005. Pile construction productivity assessment. Journal of Construction Engineering and Management conference, 131, 705-714. 
Table 1 Variables description

\begin{tabular}{|c|c|c|}
\hline No. & variables & Description \\
\hline 1 & Temperature $\left({ }^{\circ} \mathrm{C}\right)$ & Average of eight working hours of the day \\
\hline 2 & Humidity $(\%)$ & Average of eight working hours of the day \\
\hline 3 & Precipitation & $\begin{array}{l}\text { Incorporated in terms of four numerical values as follows: } \\
\text { No precipitation }=0 \text {, Light rain }=1 \text {, Rain }=2 \text {, and Snow }=3\end{array}$ \\
\hline 4 & $\begin{array}{l}\text { Wind Speed } \\
(\mathrm{km} / \mathrm{h})\end{array}$ & Average of eight working hours of the day \\
\hline 5 & Floor Height & The floor number \\
\hline 6 & Work Type & $\begin{array}{l}\text { Two types of activities will be considered as follows: Slabs } \\
=1 \text { and walls }=2\end{array}$ \\
\hline 7 & $\begin{array}{l}\text { Gang Size } \\
\text { (workers) }\end{array}$ & Number of workers (skilled + labor) in the gang \\
\hline 8 & $\begin{array}{l}\text { Labor Percent } \\
(\%)\end{array}$ & The percentage of the labor (non skilled workers) in the gang \\
\hline 9 & Driver Skills & $\begin{array}{l}1=\text { Excellent }, 2=\text { Very Good }, 3=\text { Good and } \\
\text { (depending on the number of years of experie }\end{array}$ \\
\hline 10 & Truck Status & $\begin{array}{l}1=\text { Excellent }, 2=\text { Very Good , } 3=\text { Good and } 4=\text { Bad } \\
\text { (depending on the annual safety check for insurance) }\end{array}$ \\
\hline 11 & $\begin{array}{l}\text { Road } \\
\text { Conditions }\end{array}$ & $\begin{array}{l}1 \text { = Excellent" Only new (or nearly new) superior pavements } \\
\text { are likely to be smooth enough and distress free", } 2 \text { = Very } \\
\text { Good" Pavements in this category, although not quite as } \\
\text { smooth as those described above, give a first class ride and } \\
\text { exhibit few, if any, visible signs of surface deterioration", } 3 \\
\text { = Good" The riding qualities of pavements in this category } \\
\text { are noticeably inferior to those of new pavements, and may } \\
\text { be barely tolerable for high-speed traffic" and } 4 \text { = Bad" } \\
\text { Pavements in this category have deteriorated to such an } \\
\text { extent that they affect the speed of free-flow traffic" } \\
\text { (depending on Serviceability Rating of FHWA, 2014). }\end{array}$ \\
\hline
\end{tabular}


Table 2 Variables affecting the concrete pouring process (Sample Cases)

\begin{tabular}{ccccccccc}
\hline $\begin{array}{c}\text { Temperature } \\
{ }^{\circ} \mathrm{C}\end{array}$ & Humidity \% & Precipitation & $\begin{array}{c}\text { Wind speed } \\
(\mathbf{K} / \mathbf{h})\end{array}$ & $\begin{array}{c}\text { Gang size } \\
\text { (workers) }\end{array}$ & $\begin{array}{c}\text { Labor } \\
\text { Percentage } \\
\%\end{array}$ & Floor level & Method & $\begin{array}{c}\text { Time } \\
(\mathbf{m i n})\end{array}$ \\
\hline $\mathbf{- 8 . 5}$ & 46 & 0 & 6.6 & 7 & 57 & 2 & 1 & 63.00 \\
$-\mathbf{- 1 5}$ & 50 & 0 & 12 & 5 & 60 & 2 & 1 & 53.70 \\
$\mathbf{7}$ & 90 & 1 & - & 5 & 60 & 9 & 1 & 53.40 \\
$-\mathbf{1 4 . 5}$ & 42 & 0 & 7.5 & 11 & 63 & 4 & 1 & 59.10 \\
$\mathbf{2 3}$ & 82 & 0 & 11 & 8 & - & 12 & 2 & 75.90 \\
$\mathbf{3}$ & 97 & 0 & 8 & 11 & 63 & 5 & 1 & 62.70 \\
\hline
\end{tabular}


Table 3 Variables affecting the hauling process (Sample Cases)

\begin{tabular}{ccccccc}
\hline $\begin{array}{c}\text { Temperature } \\
{ }^{\circ} \mathrm{C}\end{array}$ & Precipitation & $\begin{array}{c}\text { Wind speed } \\
(\mathbf{K} / \mathbf{h})\end{array}$ & $\begin{array}{c}\text { Driver } \\
\text { Skills }\end{array}$ & $\begin{array}{c}\text { Truck } \\
\text { Status }\end{array}$ & $\begin{array}{c}\text { Road } \\
\text { Conditions }\end{array}$ & Time (min) \\
\hline 6.5 & 0 & 11.3 & 1 & 2 & 2 & 23.75 \\
5.5 & 0 & 12 & 3 & 3 & 4 & 27.50 \\
-5 & 0 & 15.8 & 3 & 2 & 4 & 28.75 \\
7 & 1 & 5.4 & 3 & 4 & 4 & 30.62 \\
6 & 1 & 11.9 & 3 & 3 & 3 & 29.37 \\
15.5 & 0 & 18.3 & 2 & 4 & 3 & 26.25 \\
\hline
\end{tabular}


Table 4 Variables affecting the loading process (Sample Cases)

\begin{tabular}{ccccccc}
\hline $\begin{array}{c}\text { Temperature } \\
{ }^{\circ} \mathrm{C}\end{array}$ & $\begin{array}{c}\text { Humidity } \\
\%\end{array}$ & Precipitation & $\begin{array}{c}\text { Wind speed } \\
(\mathbf{K} / \mathbf{h})\end{array}$ & $\begin{array}{c}\text { Gang } \\
\text { size(workers) }\end{array}$ & $\begin{array}{c}\text { Labor } \\
\text { Percentage \% }\end{array}$ & Time (min) \\
\hline 23 & 82 & 0 & 11 & 4 & 45 & 30.36 \\
24 & 82 & 0 & 8 & 5 & 39 & 30.96 \\
16 & 73 & 1 & 14 & 4 & 36 & 25.44 \\
15 & 64 & 1 & 19 & 6 & 40 & 21.84 \\
16 & 60 & 0 & 6 & 5 & 36 & 30.36 \\
18 & 58 & 0 & 6 & 6 & 40 & 31.32 \\
\hline
\end{tabular}


Table 5 Variables affecting the return process (Sample Cases)

\begin{tabular}{ccccccc}
\hline $\begin{array}{c}\text { Temperature } \\
{ }^{\circ} \mathrm{C}\end{array}$ & Precipitation & $\begin{array}{c}\text { Wind speed } \\
(\mathbf{K} / \mathbf{h})\end{array}$ & $\begin{array}{c}\text { Driver } \\
\text { Skills }\end{array}$ & $\begin{array}{c}\text { Truck } \\
\text { Status }\end{array}$ & Road Conditions & Time (min) \\
\hline 16 & 1 & 14 & 3 & 4 & 4 & 24.25 \\
13 & 0 & 13 & 2 & 4 & 3 & 23.00 \\
21 & 0 & 8 & 1 & 2 & 2 & 18.50 \\
20 & 0 & 23 & 1 & 2 & 2 & 17.45 \\
16 & 0 & 8 & 1 & 2 & 2 & 16.50 \\
17 & 0 & 6 & 1 & 3 & 2 & 19.00 \\
\hline
\end{tabular}


Table 6 Fuzzy curve and mean square error calculations for gang size

\begin{tabular}{|c|c|c|c|c|c|c|}
\hline X5 & $\begin{array}{c}\text { X5 } \\
\text { Normalized }\end{array}$ & $\mathbf{Y}$ & $\begin{array}{c}\text { Y } \\
\text { Normalized }\end{array}$ & $M i, k(X i)$ & C5 & $(\mathrm{Ci}(\mathrm{xi}, \mathrm{k})-\mathrm{yk})^{\wedge} 2$ \\
\hline 7 & 0.33 & 63.00 & 0.46 & 3.68 & 1.70 & 10.36 \\
\hline 11 & 1.00 & 62.70 & 0.46 & 3.10 & 1.41 & 7.00 \\
\hline 5 & 0.00 & 69.90 & 0.61 & 4.03 & 2.45 & 11.69 \\
\hline 11 & 1.00 & 51.60 & 0.22 & 3.10 & 0.69 & 8.30 \\
\hline 11 & 1.00 & 48.90 & 0.16 & 3.10 & 0.51 & 8.63 \\
\hline 11 & 1.00 & 41.10 & 0.00 & 3.10 & 0.00 & 9.62 \\
\hline 7 & 0.33 & 51.60 & 0.22 & 3.68 & 0.82 & 11.96 \\
\hline 5 & 0.00 & 58.80 & 0.37 & 4.03 & 1.50 & 13.35 \\
\hline 11 & 1.00 & 66.90 & 0.54 & 3.10 & 1.69 & 6.54 \\
\hline 8 & 0.50 & 67.80 & 0.56 & 3.52 & 1.98 & 8.76 \\
\hline 9 & 0.67 & 54.00 & 0.27 & 3.37 & 0.92 & 9.62 \\
\hline 5 & 0.00 & 53.40 & 0.26 & 4.03 & 1.04 & 14.19 \\
\hline 9 & 0.67 & 46.20 & 0.11 & 3.37 & 0.36 & 10.67 \\
\hline 9 & 0.67 & 77.70 & 0.77 & 3.37 & 2.60 & 6.77 \\
\hline 5 & 0.00 & 75.60 & 0.73 & 4.03 & 2.93 & 10.88 \\
\hline 8 & 0.50 & 75.90 & 0.73 & 3.52 & 2.59 & 7.77 \\
\hline 9 & 0.67 & 77.40 & 0.77 & 3.37 & 2.58 & 6.80 \\
\hline 8 & 0.50 & 63.60 & 0.47 & 3.52 & 1.67 & 9.29 \\
\hline 11 & 1.00 & 54.60 & 0.28 & 3.10 & 0.88 & 7.94 \\
\hline 10 & 0.83 & 75.90 & 0.73 & 3.23 & 2.37 & 6.25 \\
\hline 11 & 1.00 & 78.30 & 0.78 & 3.10 & 2.43 & 5.37 \\
\hline 11 & 1.00 & 85.50 & 0.94 & 3.10 & 2.91 & 4.69 \\
\hline 9 & 0.67 & 79.80 & 0.82 & 3.37 & 2.75 & 6.54 \\
\hline 6 & 0.17 & 54.90 & 0.29 & 3.85 & 1.12 & 12.65 \\
\hline 8 & 0.50 & 76.50 & 0.75 & 3.52 & 2.63 & 7.70 \\
\hline 9 & 0.67 & 88.50 & 1.00 & 3.37 & 3.37 & 5.63 \\
\hline 9 & 0.67 & 80.40 & 0.83 & 3.37 & 2.80 & 6.47 \\
\hline 10 & 0.83 & 49.20 & 0.17 & 3.23 & 0.55 & 9.38 \\
\hline 8 & 0.50 & 54.60 & 0.28 & 3.52 & 1.00 & 10.48 \\
\hline 11 & 1.00 & 57.30 & 0.34 & 3.10 & 1.06 & 7.62 \\
\hline 11 & 1.00 & 75.60 & 0.73 & 3.10 & 2.26 & 5.64 \\
\hline 10 & 0.83 & 58.20 & 0.36 & 3.23 & 1.17 & 8.25 \\
\hline 11 & 1.00 & 74.40 & 0.70 & 3.10 & 2.18 & 5.76 \\
\hline 10 & 0.83 & 42.60 & 0.03 & 3.23 & 0.10 & 10.25 \\
\hline 11 & 1.00 & 44.40 & 0.07 & 3.10 & 0.22 & 9.19 \\
\hline
\end{tabular}




\begin{tabular}{ccccccc}
\hline 9 & 0.67 & 49.20 & 0.17 & 3.37 & 0.58 & 10.26 \\
MSE5 & & & & 8.92 & & \\
\hline
\end{tabular}

Table 7 Variables ranking using fuzzy average method

\begin{tabular}{ccc}
\hline Rank & MSEi & Variables \\
\hline 3 & 8.98 & Temperature \\
5 & 9.86 & Humidity \\
7 & 11.49 & Precipitation \\
6 & 10.72 & Wind speed \\
2 & 8.97 & Floor level \\
8 & 11.77 & Method \\
1 & 8.92 & Gang Size \\
4 & 9.67 & Labor Percentage \\
\hline
\end{tabular}


Table 8 Variables ranking using ANN

\begin{tabular}{ccc}
\hline Rank & Contribution & Variables \\
\hline 1 & 0.3191 & Temperature \\
4 & 0.1004 & Humidity \\
2 & 0.1213 & Precipitation \\
6 & 0.0946 & Wind speed \\
3 & 0.1200 & Floor level \\
8 & 0.0686 & Method \\
5 & 0.1001 & Gang Size \\
7 & 0.0754 & Labor Percentage \\
\hline
\end{tabular}


Table 9 Variables ranking using regression method

\begin{tabular}{cc}
\hline Contribution & Variables \\
\hline YES & Temperature \\
YES & Humidity \\
No & Precipitation \\
YES & Wind speed \\
YES & Floor level \\
YES & Method \\
YES & Gang Size \\
NO & Labor Percentage \\
\hline
\end{tabular}


Table 10 Fuzzy cluster membership values and task durations (Sample Cases)

\begin{tabular}{cccc}
\hline C1 & C2 & C3 & Task Duration(min) \\
\hline 0.5488 & 0.2387 & 0.2125 & 63.0 \\
0.6255 & 0.2049 & 0.1696 & 53.7 \\
0.5461 & 0.2571 & 0.1968 & 59.1 \\
0.7503 & 0.1273 & 0.1224 & 62.7 \\
0.7221 & 0.1411 & 0.1368 & 69.9 \\
0.6182 & 0.2067 & 0.1751 & 51.6 \\
0.4964 & 0.3138 & 0.1898 & 48.9 \\
0.6287 & 0.2007 & 0.1706 & 41.1 \\
0.5443 & 0.2758 & 0.1799 & 51.6 \\
0.5713 & 0.2433 & 0.1854 & 58.8 \\
0.4422 & 0.3323 & 0.2255 & 62.1 \\
0.4686 & 0.3416 & 0.1898 & 66.9 \\
0.4438 & 0.314 & 0.2422 & 67.8 \\
0.4764 & 0.3072 & 0.2164 & 54.0 \\
0.6563 & 0.1799 & 0.1638 & 53.4 \\
\hline
\end{tabular}


Table 11 A sample of candidate rules

\begin{tabular}{|c|c|c|c|c|c|c|c|c|}
\hline Rule 1 & If $\mathrm{C} 1$ is & 0.5488 & and $C 2$ is & 0.2387 & and $\mathrm{C} 3$ is & 0.2125 & Then Time is & 63.0 \\
\hline Rule 2 & If $\mathrm{C} 1$ is & 0.6255 & and $C 2$ is & 0.2049 & and $\mathrm{C} 3$ is & 0.1696 & Then Time is & 53.7 \\
\hline Rule 3 & If $\mathrm{C} 1$ is & 0.5461 & and $C 2$ is & 0.2571 & and $\mathrm{C} 3$ is & 0.1968 & Then Time is & 59.1 \\
\hline Rule 4 & If $C 1$ is & 0.7504 & and $C 2$ is & 0.1273 & and $C_{3}$ is & 0.1224 & Then Time is & 62.7 \\
\hline Rule 5 & If $C 1$ is & 0.7221 & and $C 2$ is & 0.1411 & and $\mathrm{C} 3$ is & 0.1368 & Then Time is & 69.9 \\
\hline Rule 6 & If $\mathrm{C} 1$ is & 0.6182 & and $C 2$ is & 0.2067 & and $\mathrm{C} 3$ is & 0.1751 & Then Time is & 51.6 \\
\hline Rule 7 & If $\mathrm{C} 1$ is & 0.4964 & and $C 2$ is & 0.3138 & and $\mathrm{C} 3$ is & 0.1898 & Then Time is & 48.9 \\
\hline Rule 8 & If $\mathrm{C} 1$ is & 0.6287 & and $C 2$ is & 0.2007 & and $\mathrm{C} 3$ is & 0.1706 & Then Time is & 41.1 \\
\hline Rule 9 & If $\mathrm{C} 1$ is & 0.5443 & and $C 2$ is & 0.2758 & and $\mathrm{C} 3$ is & 0.1799 & Then Time is & 51.6 \\
\hline Rule 10 & If $\mathrm{C} 1$ is & 0.5713 & and $C 2$ is & 0.2433 & 3 is & 0.1854 & Then Time is & 58.8 \\
\hline Rule 11 & If $C 1$ is & 0.4422 & and $C 2$ is & 0.3323 & 3 is & 0.2255 & Then Time is & 62.1 \\
\hline Rule 12 & If $\mathrm{C} 1$ is & 0.4686 & $C 2$ is & 0.3416 & 3 is & 0.1898 & Then $\mathrm{Ti}$ & 66.9 \\
\hline Rule 13 & If $\mathrm{C} 1$ is & 0.4438 & $C 2$ is & 0.3140 & C3 is & 0.2422 & Then Time is & 67.8 \\
\hline Rule 14 & If $\mathrm{C} 1$ is & 0.4764 & and $C 2$ is & 0.3072 & and $\mathrm{C} 3$ is & 0.2164 & Then Time is & 54 \\
\hline Rule 15 & If $\mathrm{C} 1$ is & 0.6563 & and $C 2$ is & 0.1799 & and $\mathrm{C} 3$ is & 0.1638 & Then Time is & 53.4 \\
\hline Rule 16 & If $\mathrm{C} 1$ is & 0.4630 & and $C 2$ is & 0.3096 & and $\mathrm{C} 3$ is & 0.2274 & Then Time is & 46.2 \\
\hline Rule 17 & If $\mathrm{C} 1$ is & 0.4829 & and $C 2$ is & 0.3323 & and $\mathrm{C} 3$ is & 0.1848 & Then Time is & 77.7 \\
\hline Rule 18 & If $\mathrm{C} 1$ is & 0.5289 & and $C 2$ is & 0.2885 & and $\mathrm{C} 3$ is & 0.1825 & Then Time is & 75.6 \\
\hline Rule 19 & If $C 1$ is & 0.6187 & and $C 2$ is & 0.1751 & and $C_{3}$ is & 0.2062 & Then Time is & 60.3 \\
\hline Rule 20 & If $\mathrm{C} 1$ is & 0.3454 & and $C 2$ is & 0.2165 & and $\mathrm{C} 3$ is & 0.4381 & Then Time is & 76.2 \\
\hline Rule 21 & If $\mathrm{C} 1$ is & 0.4806 & and $C 2$ is & 0.2342 & and $\mathrm{C} 3$ is & 0.2853 & Then Time is & 75.9 \\
\hline Rule 22 & If $\mathrm{C} 1$ is & 0.5063 & and $C 2$ is & 0.2639 & and $\mathrm{C} 3$ is & 0.2297 & Then Time is & 77.4 \\
\hline Rule 23 & If $\mathrm{C} 1$ is & 0.5351 & and $C 2$ is & 0.2522 & and $\mathrm{C} 3$ is & 0.2127 & Then Time is & 63.6 \\
\hline Rule 24 & If $C 1$ is & 0.5727 & and $C 2$ is & 0.2482 & and $C_{3}$ is & 0.1791 & Then Time is & 54.6 \\
\hline Rule 25 & If $\mathrm{C} 1$ is & 0.4277 & and $C 2$ is & 0.2974 & and $C_{3}$ is & 0.2748 & Then Time is & 75.9 \\
\hline Rule 26 & If $\mathrm{C} 1$ is & 0.4184 & and $C 2$ is & 0.3372 & and $\mathrm{C} 3$ is & 0.2443 & Then Time is & 78.3 \\
\hline
\end{tabular}


Table 12 A sample of the rules' effectiveness degrees

\begin{tabular}{cccc}
\hline Rules & Degree of effectiveness & Rules & Degree of effectiveness \\
\hline Rule 1 & 0.012 & Rule 19 & 0.006 \\
Rule 2 & 0.007 & Rule 20 & 0.021 \\
Rule 3 & 0.013 & Rule 21 & 0.016 \\
Rule 4 & 0.002 & Rule 22 & 0.016 \\
Rule 5 & 0.003 & Rule 23 & 0.014 \\
Rule 6 & 0.007 & Rule 24 & 0.011 \\
Rule 7 & 0.019 & Rule 25 & 0.024 \\
Rule 8 & 0.007 & Rule 26 & 0.028 \\
Rule 9 & 0.014 & Rule 27 & 0.022 \\
Rule 10 & 0.011 & Rule 28 & 0.004 \\
Rule 13 & 0.024 & Rule 31 & 0.026 \\
Rule 17 & 0.020 & Rule 35 & 0.017 \\
Rule 18 & 0.015 & Rule 36 & 0.010 \\
\hline
\end{tabular}


Table 13 A sample of a fuzzy knowledge base

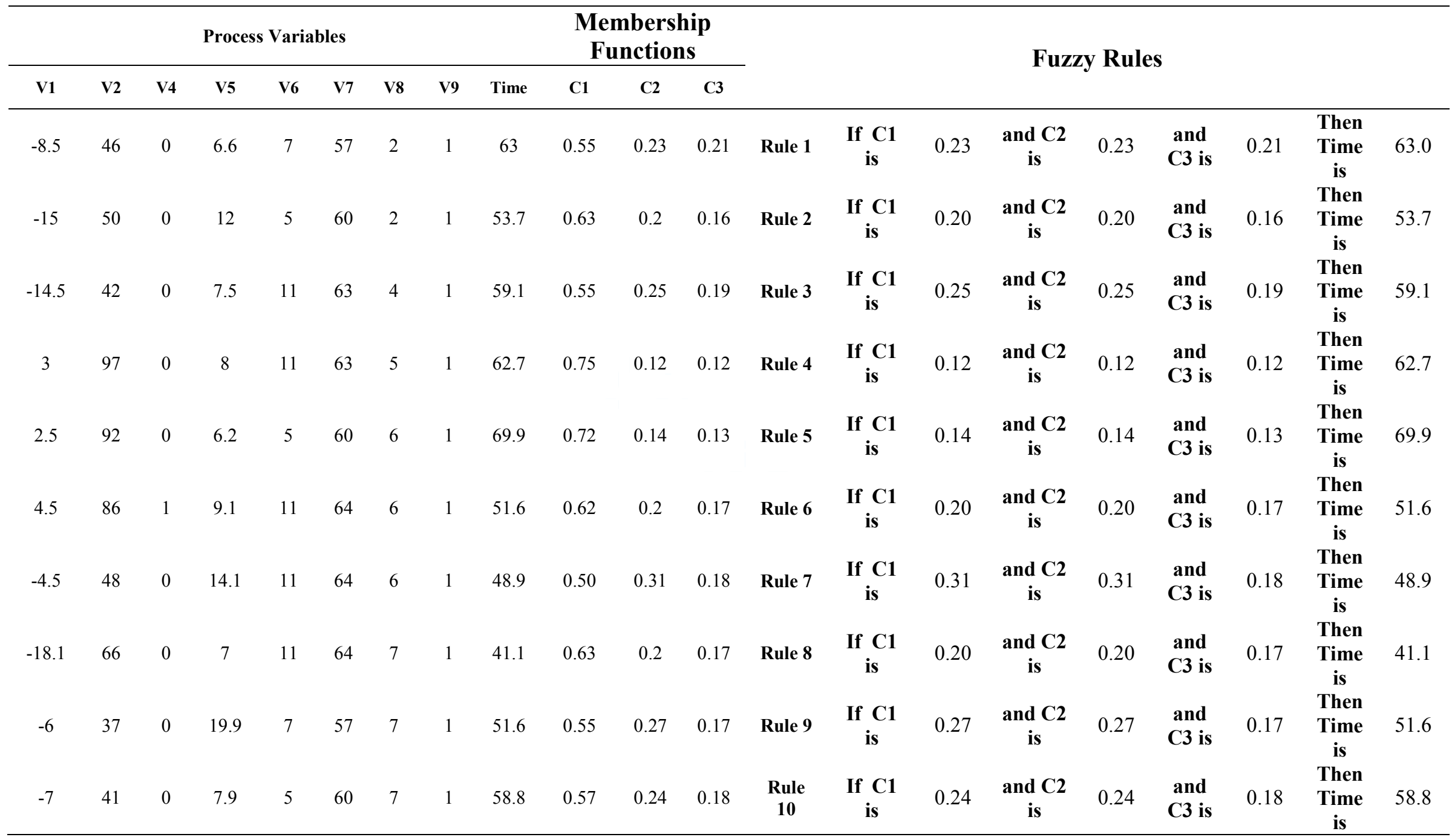


Table 14 Fuzzy knowledge base validation results

\begin{tabular}{cccccccc}
\hline C1 & C2 & C3 & Time $(\mathbf{m i n})$ & $\begin{array}{c}\text { Estimated } \\
\text { Time }(\mathbf{m i n})\end{array}$ & AIP & (Ci - Ei)^2 & ABS (Ci - Ei) \\
\hline 0.6255 & 0.2049 & 0.1696 & 53.7 & 52.9261 & 0.0144 & 0.5989 & 0.7739 \\
0.5461 & 0.2571 & 0.1968 & 59.1 & 57.3813 & 0.0291 & 2.9539 & 1.7187 \\
0.4422 & 0.3323 & 0.2255 & 62.1 & 65.3717 & 0.0527 & 10.7041 & 3.2717 \\
0.6187 & 0.1751 & 0.2062 & 60.3 & 57.8351 & 0.0409 & 6.0757 & 2.4649 \\
0.3454 & 0.2165 & 0.4381 & 76.2 & 68.3471 & 0.1031 & 61.6678 & 7.8529 \\
0.1668 & 0.1529 & 0.6803 & 71.4 & 74.8541 & 0.0484 & 11.9311 & 3.4541 \\
0.49 & 0.2588 & 0.2512 & 69.3 & 56.7075 & 0.1817 & 158.5717 & 12.5925 \\
0.5224 & 0.2316 & 0.246 & 70.2 & 54.7342 & 0.2203 & 239.1914 & 15.4658 \\
0.5254 & 0.2468 & 0.2278 & 55.8 & 57.0190 & 0.0218 & 1.4861 & 1.2190 \\
0.4208 & 0.2456 & 0.3336 & 55.5 & 61.3393 & 0.1052 & 34.0975 & 5.8393 \\
AIP (\%) & 8 & AVP (\%) & 92 & RMSE & 2 & MAE & 5 \\
\hline
\end{tabular}




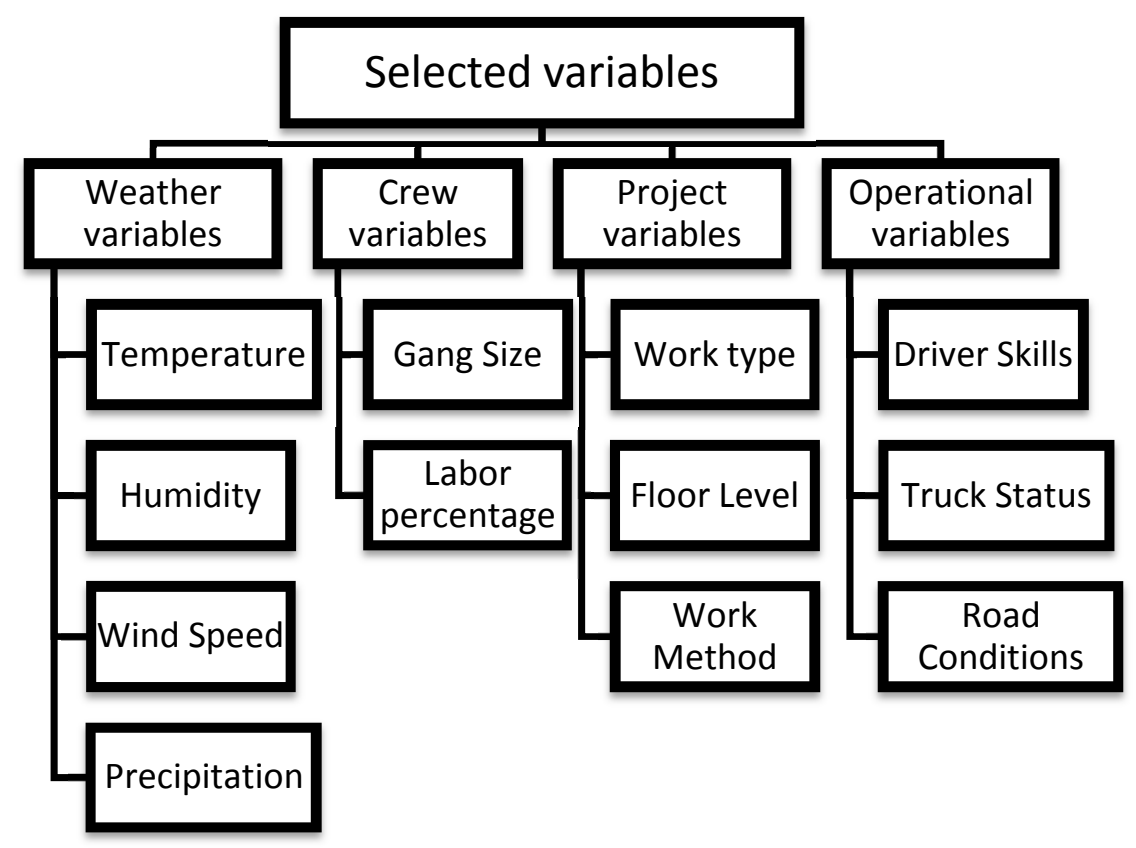

Figure 1 The considered variables in the present study 


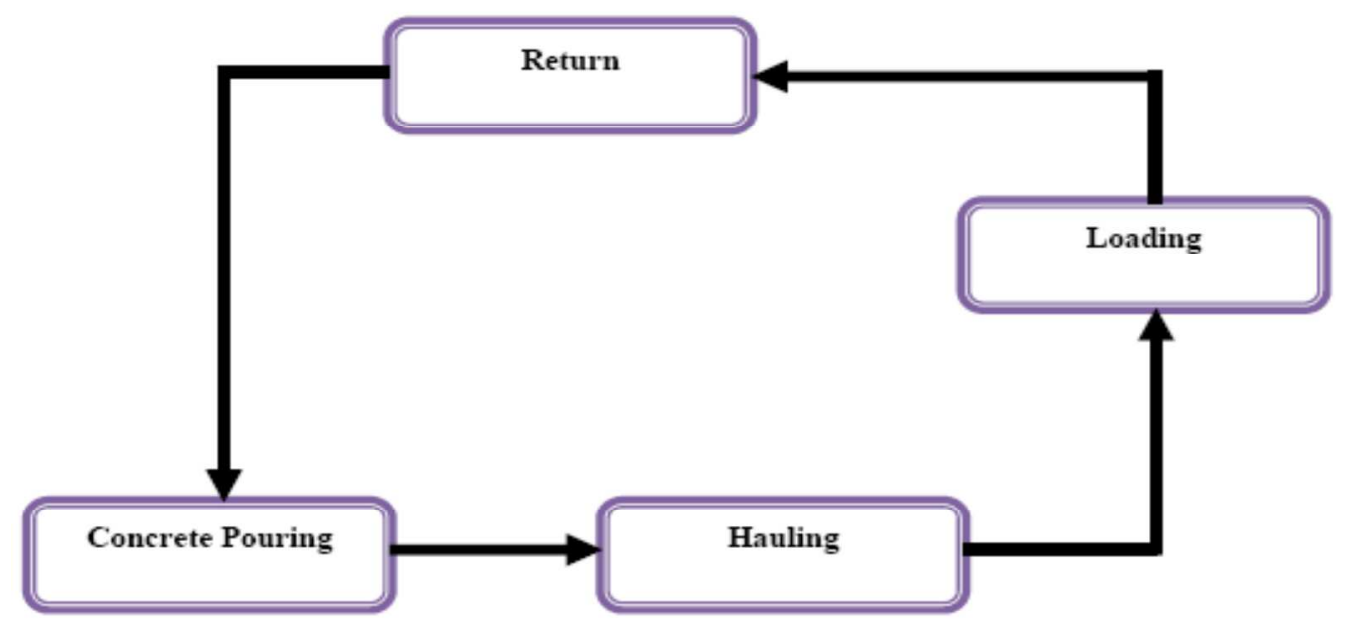

Figure 2 Model of the concrete pouring operation 


\section{Processes Data Sets}

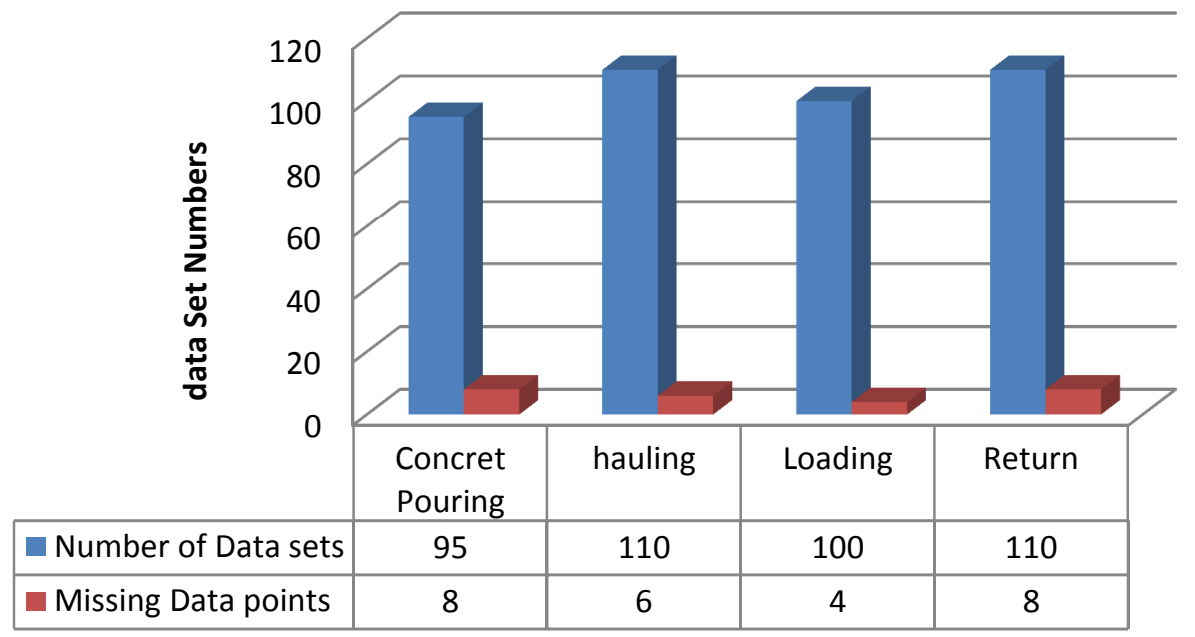

Figure 3 The data sets of concrete pouring operation 


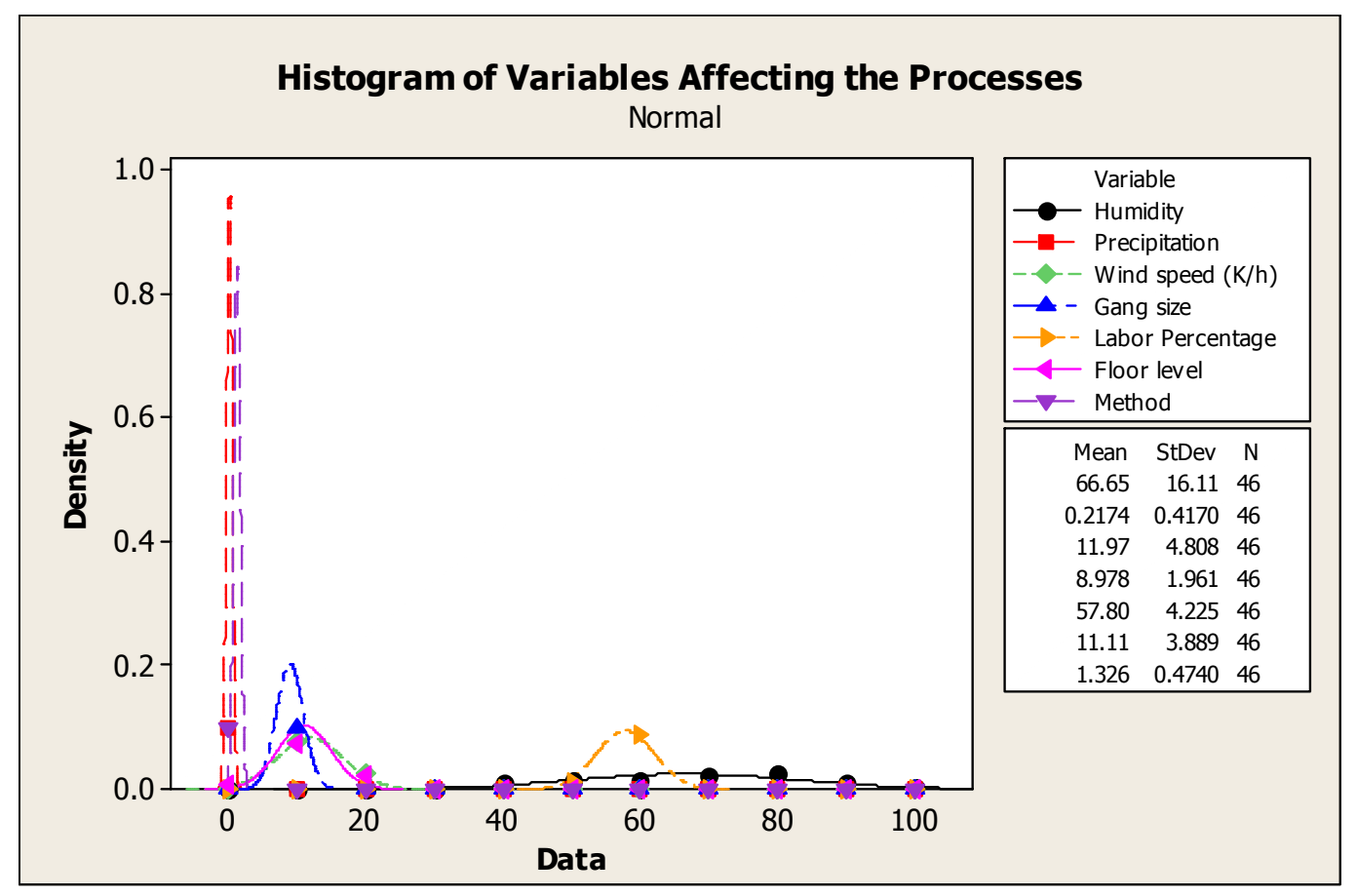

Figure 4 Statistical parameters and probability density functions 


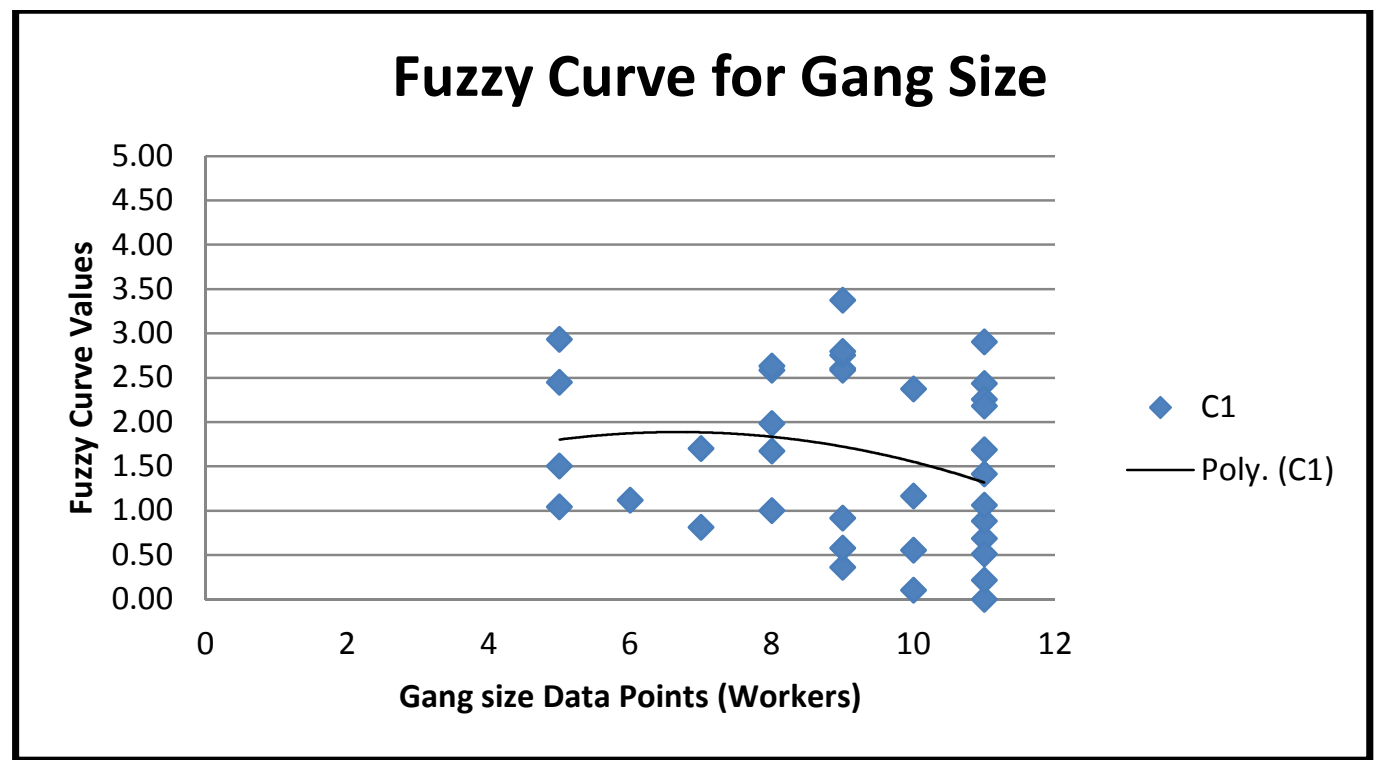

Figure 5 Fuzzy curve for Gang Size 


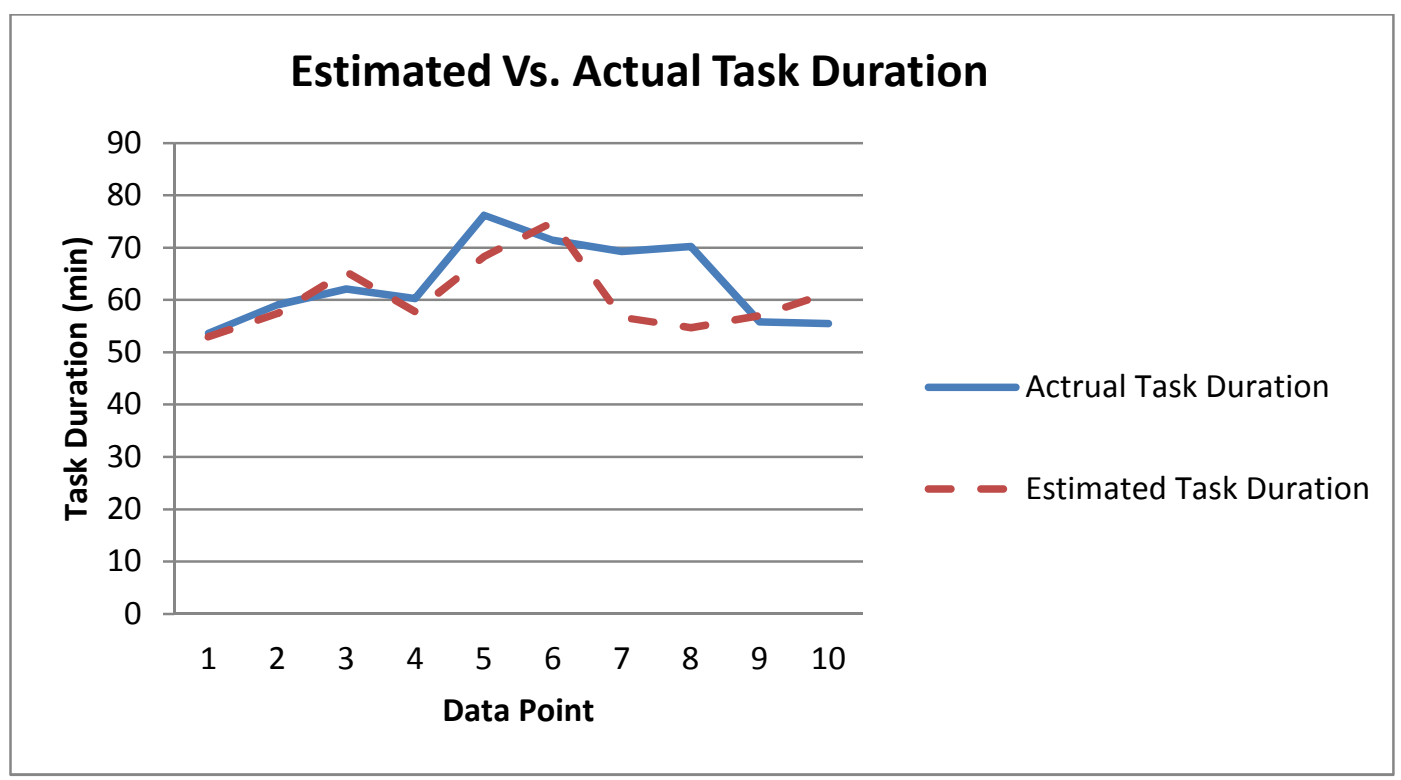

Figure 6 Estimated vs. actual task duration 